\title{
Pedagogia crítica e o legado de Paulo Freire para a democratização da educação: entrevista com Henry Giroux
}

\author{
Maria Vieira Silva ${ }^{1}$ \\ ORCID: 0000-0002-4510-0844 \\ Maria Veranilda Mota Campos ${ }^{2}$ \\ ORCID: 0000-0002-5392-2629
}

\section{Resumo}

Paulo Freire e Henry Giroux, autores de teorizações densas e originais, referências para a educação ao longo de décadas, ressignificam conceitos para tonificar a Pedagogia Crítica e sedimentar relações democráticas no ato educativo. No contexto do centenário de Paulo Freire, a presente entrevista proporciona o encontro entre esses dois grandes intelectuais, atados por uma afınidade epistemológica nutrida por uma longa e sólida amizade. Mediante memórias e olhares interpretativos a respeito da teoria freireana, Giroux reconhece a importância do legado de Paulo Freire e reafırma a relevância política e pedagógica de sua teoria como dimensão crucial para a democratização da escola e da sociedade.

\section{Palavras-chave}

Teoria freireana - Pedagogia crítica - Democratização da educação.

\section{Critical pedagogy and the legacy of Paulo Freire for the democratisation of education: interview with Henry Giroux}

\section{Abstract}

Paulo Freire and Henry Giroux, authors of dense and original theorisations and references for education for decades, resignify concepts to tone Critical Pedagogy and sediment democratic relations in the educational act. In the context of Paulo Freire's centenary, this interview covers the meeting between these two great intellectuals, bound by an

1- Universidade Federal de Uberlândia, Minas Gerais (MG) - Brasil. Contato: mvieiraufu@gmail.com

2- Universidade Federal de Viçosa, Minas Gerais (MG) - Brasil. Contato: veranilda.mota@ufv.br 
epistemological affinity nourished by a long and solid friendship. Through his memories and interpretation of Freire's theory, Giroux recognises the importance of Paulo Freire's legacy, and reaffirms a political and pedagogical approach to his theory as a crucial dimension for the democratisation of school and society.

\section{Keywords}

Freirean theory - Critical pedagogy - Democratisation of education.

\section{Pedagogía Crítica y el legado de Paulo Freire para la democratización de la educación: entrevista a Henry Giroux}

\section{Resumen}

Paulo Freire y Henry Giroux, autores de densas y originales teorizaciones, referencias para la educación a lo largo de décadas, redefinen conceptos para vigorizar la pedagogía crítica y consolidar las relaciones democráticas en la acción educativa. En el contexto del centenario de Paulo Freire, la presente entrevista ofrece el encuentro entre estos dos grandes intelectuales, unidos por una afinidad epistemológica alimentada por una larga y sólida amistad. A través de memorias y visions interpretativas de la teoría de Freire, Giroux reconoce la importancia del legado de Paulo Freire y reafirma la relevancia politica y pedagógica de su teoría como una dimensión crucial para la democratización de la escuela y la sociedad.

\section{Palabras clave}

Teoría freireana - Pedagogía crítica - Democratización de la educación. 


\section{Apresentação}

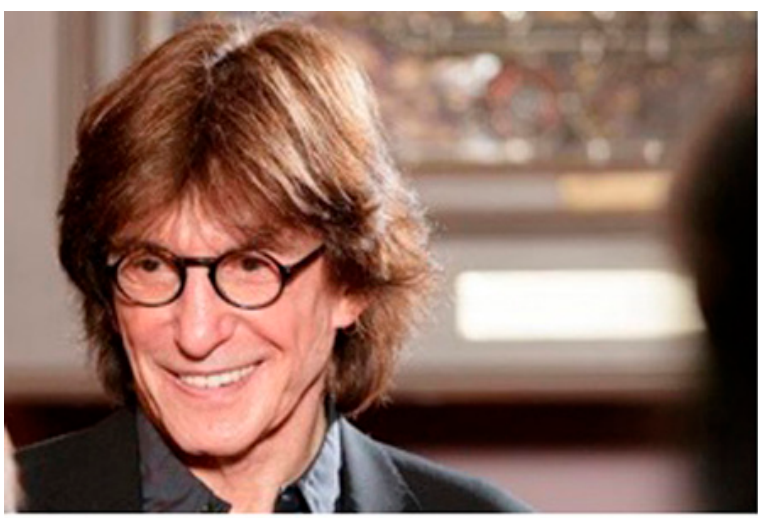

Fonte: Henry Giroux - acervo pessoal.
Qual o tempo natural da memória? Seria o passado? Eu responderia: sem dúvida. 0 tempo da memória é o presente, mas ela necessita do passado. 0 tempo da memória é o presente por que é no presente que se constrói a memória. A memória não se constrói no passado, se constrói no presente. Le Goff

Os ciclos temporais são simbologias, constructos sociais, mas, essas demarcações de temporalidades instam-nos a reconstituir trajetórias, acessar memórias e tecer narrativas para atualizar o presente. De acordo com Le Goff (2003, p. 119): “memória é um conjunto de funções psíquicas, graças às quais o homem pode atualizar impressões, informações passadas ou informações que ele representa como passadas”. Ainda segundo o historiador, "o interesse do passado está em esclarecer o presente; o passado é atingido a partir do presente (método regressivo de Bloch)” (LE GOFF, 2003, p. 119). Sob tal prisma, o presente texto apresenta elementos do pensamento de Paulo Freire, o qual foi constituído e transversalizado por diferentes contextos históricos, visando a "atualizar o passado" e remontar o presente, uma vez que passado e o presente entretecem ao longo da história.

As memórias de parte do legado de Paulo Freire, aqui disponibilizadas, remetem a acontecimentos e formulações teóricas imbricadas em um contexto social que o constituiu como sujeito. Assim, não é demais ressaltar que as identidades individuais não se encontram em um vácuo histórico, mas são produzidas pelas experiências substantivadas no tecido social. Ainda de acordo com Le Goff (2003), a aplicação à história dos dados da filosofia, da ciência, da experiência individual e coletiva tende a introduzir, junto desses quadros mensuráveis do tempo histórico, a noção de duração, de tempo vivido, de tempos múltiplos e relativos, de tempos subjetivos ou simbólicos. 0 tempo histórico encontra, num nível muito sofisticado, o velho tempo da memória, que atravessa a história e a alimenta.

As acepções e os significados atribuídos à memória indicam a preservação de recordações e apontam também para um movimento de vida. Assim pensando, de certo modo, a memória pode também nos preservar da morte pelo esquecimento. De acordo com Chaui:

[...] a memória é uma evocação do passado. É a capacidade humana de reter e guardar o tempo que se foi, salvando-o da perda total, [...] é uma atualização do passado ou a presentificação do passado e é também registro do presente para que permaneça como lembrança. (CHAUÍ, 1996, p. 125). 
Os registros aqui dispostos são fragmentos de concepções educacionais e políticas de Paulo Freire - uma das principais referências do pensamento crítico mundial - que atravessaram o tempo, transpuseram fronteiras e foram acolhidos por expressivos intelectuais, como Henry Giroux. Essas memórias, evocadas e compostas por Giroux, por óbvio, não abarcam a multiplicidade e a totalidade de elementos que têm constituído a corrente de pensamento de Freire ao longo de décadas, mas se trata de um exercício seletivo dos momentos significativos do encontro entre esses pensadores. 0 testemunho oral permite pensar que o passado é concebido como convocável pelos sujeitos do presente para mostrar/dizer ao homem o seu próprio tempo (LE GOFF, 2003).

Em 2021, Paulo Freire completa um século de existência e, nesse percurso, suas teorizações, sua ética e sua forma de pensar o mundo e a política deixaram marcas indeléveis na Pedagogia Crítica. Espécie de mosaico de percursos individuais ancorado em formulações que bifurcam teorizações mediatizadas pelo passado e presente, este trabalho disponibiliza alguns elementos do pensamento de Paulo Freire a partir de olhares interpretativos de Henry Giroux.

\section{Um encontro que marca a história}

Paulo Reglus Neves Freire chegou ao mundo em 19 de setembro de 1921. Patrono da educação brasileira por meio da Lei 12.612 (BRASIL, 2012), as obras desse grande educador pernambucano são lidas e referenciadas por pesquisadores e militantes de movimentos sociais de diferentes países, em razão da consistência e originalidade de suas teorizações. Ancoradas em perspectivas epistemológicas e metodológicas de base crítica e anticapitalista, as formulações de Freire são dedicadas aos esfarrapados do mundo e daqueles que tiveram sua voz silenciada e sua vez subjugada.

De acordo com Santiago (s/d), a experiência profissional de Freire foi construída em diferentes espaços e níveis educacionais no âmbito escolar e do movimento social a partir do Colégio Osvaldo Cruz, estendendo-se pelo SESI (Serviço Social da Indústria), Instituto Capibaribe do Recife, pela Escola de Serviço Social, Escola de Belas Artes, Serviço de Extensão Cultural do Recife da Universidade do Recife, atualmente, Universidade Federal de Pernambuco, espalhando-se pelo mundo nas mais diversas formas de colaboração.

A Educação Popular e a Educação de Jovens e Adultos foram bases fundantes das ideias de Freire, assumem visibilidade, constituindo-se em referentes importantes para a Pedagogia Crítica. Suas formulações teórico-práticas propõem uma educação para a transformação social e no empoderamento de sujeitos mediatizados por práticas transformadoras e consciência crítica. Assim, Paulo Freire não foi um mero espectador da História de seu povo e, longe de adotar posturas neutras, assumiu posição de porta-voz de vozes silenciadas pelas dinâmicas de poder e colocou seu trabalho e sua visão sociológica, histórica e filosófica a serviço da transformação das desiguais estruturas sociais.

Coerente com sua visão do homem e da história, ele busca compreender esse processo de transformação pondo a ênfase menos nas características estruturais que na crise de valores. Não obstante as estruturas se encontrem presentes em sua análise, são os estados da consciência a área privilegiada de sua reflexão. E ainda uma vez 
se observa, já agora na visão sociológica e histórica implícita em sua concepção educacional, uma solidariedade fundamental entre a teoria e a prática. Sua visão sociológica, centrada sobre o mundo da consciência, constitui-se a partir de uma preocupação fundamentalmente educativa.

Henry Armand Giroux, professor e pesquisador do Departamento de Estudos Culturais, da Faculdade de Ciências Humanas, MCMaster University, Canadá, é considerado um dos principais pensadores da teoria crítica na educação e é reconhecido pelas discussões acerca da educação contemporânea e sua proximidade com Paulo Freire. É conhecido pelos educadores no Brasil por meio dos seus trabalhos sobre a Pedagogia Radical, nos quais aponta o papel do professor como agente intelectual público e exalta a importância dos movimentos de resistência na educação. Para ele, a pedagogia deve assumir um papel central para as políticas públicas.

Giroux cresceu em um bairro operário em meio à violência, à lealdade e à solidariedade. Como ele afırma, no seu site ${ }^{3}$, não era possível sobreviver naquele bairro sem amigos, sem um grupo: "Pra mim a justiça social foi forjada nos laços de solidariedade e na necessidade de se reconhecer noções do bem comum e a importância do social". Ao ingressar em um programa de formação de professores, logo percebeu as dimensões éticas e políticas do ensino, bem como a importância de se desenvolver uma consciência crítica e uma cultura formativa para a viabilização de uma sociedade democrática.

Em 1975, ao ler o livro Pedagogia do Oprimido, de Paulo Freire, deparou-se com uma linguagem que lhe permitiu não só explicar, mas compreender um sentido mais amplo do que ele fazia como professor de História, no Ensino Médio, onde atuou no período de 1968 a 1975.

0 encontro entre Giroux e Paulo Feire foi marcado por uma preocupação comum entre eles: a busca de construir significados, de formar uma teoria crítica da educação a partir da intersecção entre o papel da educação, cultura e vida pública.

Este trabalho procura evidenciar as marcas profundas da teoria freireana sedimentadas no pensamento e no trabalho de Giroux. Muitos aspectos em comum marcam essa amizade iniciada no começo dos anos oitenta. Eles fazem aniversário quase no mesmo dia de setembro. Giroux completa anos no dia 18 e Paulo, no dia 19. Apesar dos vinte e dois anos de diferença de idade, estabeleceram uma amizade teórica e pessoal, objetiva e subjetiva coerentemente com o fundamento da teoria crítica.

Paulo Freire, ao prefaciar o livro Teoria crítica e resistência em educação (GIROUX, 1986), contou da sua satisfação ao emitir parecer favorável de um artigo e da manifestação de querer conhecer seu jovem autor:

Meu primeiro contato com o pensamento inquieto de Giroux começou há algum tempo, durante uma tarde de verão suiço em meu gabinete, dois ou três anos antes de meu retorno ao Brasil, depois de dezesseis anos de exílio. [...] A seriedade do trabalho, sua clareza, seu rigor - tudo teve um profundo impacto sobre mim. (FREIRE, 1986, p. 09).

\section{3- https://www.henryagiroux.com/about}


A partir desse encontro, a influência de Paulo Freire na obra de Giroux ampliou-se e ele procurou "ligar o trabalho de Paulo Freire com tradições orientadas pelos escritos de Marx, Gramsci, autores da Escola de Frankfurt e outros.” (GIROUX, 1986, p. 12). Freire (1999, p. ix) reconhece que "o que caracteriza Giroux como teórico esplêndido é sua insistência para que compreendamos os complexos relacionamentos entre os objetos”.

A criatividade de Giroux, sua abertura para as questões, sua curiosidade, sua dúvida, sua incerteza em relação às certezas, sua coragem de assumir riscos e suas abordagens metodológicas e teóricas rigorosas de temas importantes o caracterizam como um dos grandes pensadores de seu tempo... (FREIRE, 1999, p. ix).

A centralidade deste trabalho é a fala do próprio Giroux através de uma entrevista cedida em um momento em que o pensamento de Paulo Freire tem sido desqualificado por grupos neoconservadores, no Brasil. Tal fato é analisado por Giroux como reação de desespero político, pois a obra de Paulo Freire, nas palavras ditas nesta entrevista: "clama por uma mudança radical na consciência”. Em 1983, Giroux, já reconhecia essa base determinante do pensamento freireano. "Meu camarada e amigo, Paulo Freire, vem argumentando há mais de vinte anos que a política de luta está associada a processos culturais que levam a sério a produção do conhecimento radical” (GIROUX, 1986, p. 12).

Frei Beto evidenciou essa característica ao exaltar a longitude do método de alfabetização que ensina mais do que ler palavras e que provoca mudanças na forma de o estudante ver o mundo. Quando nas cartilhas se ensinava, sem significado, que "Ivo viu a uva", Paulo Freire mostra que Ivo viu muito mais que a uva, ele viu que "a fruta não resulta do trabalho humano. É criação, é natureza”. Ivo também viu que colher a uva é cultura, que o "trabalho humaniza a natureza, e, ao realizá-lo o homem e a mulher se humanizam”. A partir do diálogo, Ivo viu também que a uva é colhida por boias-frias que são explorados e que através do trabalho se instaura a vida social. Assim, "Ivo viu a uva e Paulo Freire mostrou-lhe os cachos, a parreira, a plantação inteira." (FREI BETO, 2006, p. 617).

São muitos os pontos de confluência entre Freire e Giroux, mas, talvez, um dos aspectos mais estruturais que sedimenta nexos entre os pensadores seja a comunhão de concepções políticas e as utopias em prol da construção de outra sociedade. Nas próprias palavras de Giroux, Paulo Freire foi um dos educadores mais importantes do século XX e ocupa uma posição sagrada entre os fundadores da Pedagogia Crítica - movimento educacional guiado pela paixão e com o princípio de ajudar os alunos a desenvolver uma consciência de liberdade, reconhecer tendências autoritárias e conectar o conhecimento e a verdade; aprender a ler a palavra e o mundo como parte de uma luta mais ampla por justiça e democracia:

At a time when memory is being erased and the political relevance of education is dismissed in the embrace of the language of measurement and quantification, it is all the more important to remember the legacy and work of Paulo Freire. Paulo Freire was one of the most important educators of the twentieth century. He occupies a hallowed position among the founders of "critical pedagogy" - the educational movement guided by both passion and principle to help 
students develop a consciousness of freedom, recognize authoritarian tendencies, empower the imagination, connect knowledge and truth to power, and learn to read both the word and the world as part of a broader struggle for agency, justice, and democracy. ${ }^{4}$ (GIROUX, 2016, p. 297).

Em outra obra, Giroux destaca o papel da educação como uma forma de política cultural que liga a teoria e prática social aos aspectos mais profundos de emancipação e um referencial de mudança a serviço de uma nova sociedade:

Freire introduz uma nova dimensão na teoria e prática educacional radical. Eu digo nova porque ele liga processo de luta às particularidades das vidas das pessoas e ao mesmo tempo argumenta em prol de uma fé no poder dos oprimidos para lutarem no interesse de sua própria libertação. Esta é uma noção de educação que não provém apenas da análise crítica e do pessimismo orweliano; é um discurso que cria um novo ponto de partida ao tentar fazer com que a esperança seja realizável e o desespero não convincente. A educação na visão de Freire torna-se tanto ideal quanto referencial de mudança a serviço de uma nova espécie de sociedade. Enquanto ideal, a educação refere-se a uma forma de política cultural que transcende os limites teóricos de qualquer doutrina política específica, enquanto ao mesmo tempo liga a teoria e prática social aos aspectos mais profundos de emancipação. Conseqüentemente, como expressão de uma teoria social radical, a política cultural de Freire é mais ampla e mais fundamental do que qualquer discurso político específico, como, por exemplo, a teoria marxista clássica, ponto que muitas vezes confunde seus críticos. Na verdade, ela representa um discurso teórico cujos interesses subjacentes se formam em torno de uma luta contra todas as formas de dominação subjetiva e objetiva, assim como uma luta em prol de formas de conhecimento, habilidades e relações sociais que promovam as condições para a emancipação social e, portanto, a auto-emancipação. (GIROUX, 1997a, p. 146).

Sob tal perspectiva, Freire e Giroux acreditam que uma das tarefas fundamentais dos educadores - sob a lógica da pedagogia crítica - é contribuir com a construção de um mundo socialmente justo mediante processos que visem a alterar os fundamentos das assimetrias de poder, rompendo com mecanismos que produzem a legitimação das desigualdades e corrosão da dignidade humana.

\section{O ataque à educação}

Este momento de ataques à educação emana resistência. 0 discurso imobilizante que tem assolado nosso tempo, com sua tônica fatalista, já dizia Paulo Freire (2017, p. 21), "insiste em convencer-nos de que nada podemos fazer contra a realidade social". Giroux tem trabalhado para ampliar o conhecimento da relação entre educação e vida política,

4- Tradução nossa: "Numa época em que a memória se apaga e a relevância política da educação é descartada em razão do entrelaçamento da linguagem da medida e da quantificação, é ainda mais importante lembrar o legado e a obra de Paulo Freire. Paulo Freire foi um dos mais importantes educadores do século XX. Ele ocupa uma posição sagrada entre os fundadores da "pedagogia crítica" - o movimento educacional guiado pela paixão e pelos princípios para ajudar os alunos a desenvolver uma consciência de liberdade, reconhecer tendências autoritárias, fortalecer a imaginação, conectar o conhecimento e a verdade ao poder e aprender a ler a palavra e o mundo como parte de uma luta mais ampla por agência, justiça e democracia". 
tem assumido o compromisso com práticas democráticas que, como tem declarado, devem ser aprendidas e reaprendidas a cada geração sucessivamente. Tem defendido que:

[...] as escolas são as principais instituições para educar os alunos para a vida pública [...] que as escolas devem funcionar para proporcionar aos alunos o conhecimento, o caráter e a visão moral que edificam a coragem cívica. (GIROUX, 1999, p. 29).

Nessa perspectiva, a escola tem a possibilidade de ampliar a visão de mundo dos estudantes, de suas relações com os outros e consigo mesmo. A educação, portanto, é uma luta pelo futuro que queremos para os jovens.

\section{Afirmação da pedagogia radical: diálogo com Giroux sobre Paulo Freire}

A crise da política é também a crise da educação e a crise de consciência. Henri Giroux

Prof. Giroux, manifestamos nossa imensa alegria e gratidão por oportunizar diálogos sobre vida e obra de Paulo Freire, pois seu trabalho tem marcas profundas da teoria freireana e constitui-se em um importante veículo de difusão de seus ideais. Assim, seria bom iniciarmos nosso diálogo recuperando suas memórias da aproximação com Paulo Freire e as marcas mais potentes que ele deixou em sua trajetória pessoal e em seu ativismo político e acadêmico.

Conheci o trabalho de Freire pela primeira vez quando era professor do ensino médio, no início dos anos 1970. Eu estava tentando teorizar o que significava engajar meus alunos de maneiras que provassem ser significativas a fim de que se tornassem críticos e transformadores. A questão de como conectar a pedagogia às vidas diárias dos meus alunos e, ao mesmo tempo, capacitá-los a serem atores críticos e engajados na luta por igualdade, justiça e liberdade foi fundamental para o meu trabalho. 0 que me faltou inicialmente foi uma linguagem teórica. Isso mudou quando fui apresentado ao trabalho de Paulo sobre pedagogia e sua compreensão da escolaridade como um local de luta por significados atribuídos, atuação, valores e uma visão democrática radical do futuro.

Que aspectos da obra de Paulo Freire poderia destacar como legados fundamentais na incessante luta contra as várias formas de opressão de estratos marginalizados?

0 trabalho de Paulo foi crucial para definir alfabetização como um projeto pedagógico e político vinculado à capacitação dos alunos como atores criticamente engajados. 0 que ele entendeu foi que as questões privadas teriam que estar vinculadas a problemas sociais maiores e que a educação era fundamental para tal projeto. A maneira como as pessoas pensam, como 
suas identidades são construídas e como elas veem a si mesmas, seu relacionamento com os outros e com o mundo mais amplo foi crucial para produzir atores informados capazes de intervir no mundo. Alfabetização para Freire era uma forma de entender a conexão entre conhecimento, poder e o projeto de luta sem fim por ambos, o que ele chamava de ser humano inacabado e a luta contínua por justiça e democracia. Ele rejeitou a noção de neutralidade da escolaridade, do professor e do propósito tanto da pedagogia quanto da escolaridade. Ele acreditava que escolas e a noção mais ampla de educação tinham a responsabilidade de abordar problemas sociais e políticos importantes e que escolaridade e educação em um sentido mais amplo eram as esferas mais importantes para a criação de agentes capazes de abolir um sistema capitalista e outros sistemas de opressão.

Sem pretender fazer enquadramentos ortodoxos e obsoletos, mas, na tentativa de um desenho do quadro teórico do pensamento de Paulo Freire, poderia nos dizer qual sua percepção acerca da base epistemológica e metodológica de sua obra?

A base epistemológica do trabalho de Freire foi descobrir como o poder funciona pedagogicamente a serviço da opressão e, ao mesmo tempo, abraçar uma noção de poder e alfabetização crítica, consciência cívica e agência crítica dentro de uma compreensão abrangente da política e da ordem social mais ampla. Ele recusou o fetiche dos métodos, a racionalidade instrumental e a separação do conhecimento em elementos distintos e fragmentados. Freire prestou um grande serviço teórico ao argumentar que educação e pedagogia não podem se sustentar no altar de métodos simplificados ou na adoração de objetivos instrumentais, tal como transformar indivíduos em meros trabalhadores na força de trabalho global mais ampla. Ele foi um teórico do todo e a teoria social e política foram as ferramentas para dar sentido à busca de novas formas de subjetividade e compreensões alternativas e democráticas da sociedade. No cerne de sua compreensão da educação estava a crença de que a busca por justiça nunca termina e que a pedagogia crítica é central para tal projeto, não como uma busca individual, mas como um modo coletivo de resistência. Freire acreditava que nenhuma sociedade democrática poderia existir sem as instituições que produzem cidadãos críticos e engajados, e que não há democracia sem cidadãos informados e que acreditam que uma sociedade verdadeiramente democrática é aquela que tudo questiona. Isso significa aprender com a trajetória da história, desenvolver uma abordagem abrangente e dialética para conectar diversas questões sociais e trabalhar duro para repensar por qual tipo de futuro vale a pena lutar.

Estamos vivenciando distopias e indignações face aos acintes à frágil democracia e aos recorrentes processos de perda de direitos sociais instaurados. Em seu artigo Pedagogia Crítica, Paulo Freire, e a coragem para ser político (2016), você afirma que Paulo passou a vida guiado pelas crenças de que valia a pena lutar pelos elementos radicais da democracia e que a democracia não pode durar sem a cultura formativa que a torna possivel. Em sua perspectiva, qual o papel do meio acadêmico e dos movimentos sociais na construção e consolidação de uma sociedade democrática? 
No espírito de Paulo Freire, o ambiente acadêmico deve ser uma esfera pública democrática que usa seus recursos e educa seus professores/professorado para se engajarem ativamente na busca pela verdade, justiça e igualdade. Tais instituições devem ser controladas por professores que modelem como atuar como agentes sociais em seu diálogo com os alunos, possibilitando tanto a participação nas práticas pedagógicas que ampliam e aprofundam tanto seu papel como agentes críticos quanto na luta pela vida pública democrática, em particular a sociedade desenvolvida com base no socialismo democrático. A educação é um dos poucos locais públicos restantes onde as ideias, atitudes, valores e objetivos podem ser ensinados que permitem aos alunos responsabilizar o poder, questionar a autoridade, se envolver com o legado de grandes obras científicas e literárias e levar a sério os desafios iminentes de um globo que se tornou cada vez mais autoritário. Os movimentos sociais, bem como os acadêmicos, têm a responsabilidade de usar seus conhecimentos, recursos, habilidades sociais e energias para abordar problemas sociais importantes enquanto fazem as pessoas pensarem criticamente, serem autorreflexivas sobre as questões públicas e o mundo em que vivem e aprender como governar em vez de ser governado. As instituições acadêmicas e os movimentos sociais devem ser faróis de uma esperança militante, proporcionando condições para que os alunos e outros pensem de outra forma para intervir no mundo de forma crítica e informada. Para Freire, pensar criticamente nunca foi suficiente. A pedagogia crítica parte da premissa de que estar informado é um pré-requisito não apenas para enfrentar graves injustiças sociais, pobreza massiva e pedagogias que paralisam a imaginação, mas também para intervir no mundo para mudá-lo.

\section{Qual a importância da atuação de Paulo Freire para o fortalecimento do professor e para a ressignificação do currículo?}

No cerne do trabalho de Freire está essa suposição de que professores não apenas são centrais para o processo pedagógico, mas que eles devem ter controle sobre as condições de trabalho. Ao mesmo tempo, ele aponta para a necessidade de serem críticos, informados, dispostos a correr riscos e a desafiar o poder dos que praticam o comércio da injustiça, produzem uma indiferença paralisante à justiça social e concentra o poder nas mãos de poucos. Freire deixou claro em todo o seu trabalho que o currículo não é um roteiro predeterminado e sem vida de catálogo de métodos. Este último cria zonas mortas da imaginação, desqualifica professores e reproduz pedagogias de repressão. A obra de Paulo fornece indicadores teóricos e uma linguagem que oferece esperança contra uma gama debilitante de pedagogias que funcionam amplamente a serviço do autoritarismo, especialmente em uma época marcada pela ascensão do populismo de direita e uma versão atualizada do fascismo. Freire rejeita a ênfase neoliberal em uma noção regressiva de interesse próprio com seu ferrão e forma brutalizante de individualismo. Ele também rejeita o colapso do político em pessoal e terapêutico. Nesse caso, questões de resistência coletiva, opressão sistêmica e a capacidade de traduzir problemas privados em forças mais amplas e interligadas são substituídas pelo discurso de autoajuda, a linguagem privatizada da responsabilidade individual e o apelo à elevação emocional e sentimentos positivos. Ao contrário, seu trabalho abraça uma noção robusta de justiça social, do contrato social e da importância dos valores compartilhados 
e do bem público. Por isso, Freire é considerado perigoso para os vários liberais, conservadores e autoritários que abraçam a noção venenosa de que a sociedade não existe e que o mercado deve governar toda a vida social.

Paulo Freire tem sofrido ataques pífios e desqualificadores de sua obra, por grupos neoconservadores (inclusive por quadros do alto escalão do Governo Bolsonaro), que o acusam de ser a principal referência para a doutrinação ideológica esquerdista. Essas manifestações de direita do Brasil têm raízes históricas, visando a perenizar processos de exclusão. Mas, no atual cenário, como pensar os efeitos desse modus operandi do pensamento ultraconservador difuso na atmosfera social e as possibilidades de resistência?

A obra de Freire é descartada de forma simplista como um ato de desespero político, porque clama por uma mudança radical na consciência, no desenvolvimento de uma cultura cívica democrática, no surgimento de movimentos democráticos de massa e ao fim do ataque autoritário aos direitos políticos, social e econômica que devem beneficiar todas as pessoas. Os governos de direita têm pavor da democracia e do papel que a educação crítica pode desempenhar ao fornecer condições para que professores, alunos e outros trabalhadores culturais analisem e transformem governos antidemocráticos e as ferramentas ideológicas e políticas de poder que eles usam para reproduzir a si mesmos. A visão de Freire sobre educação, pedagogia e resistência é muito perigosa para os Bolsonaros do mundo, porque torna visivel seus usos insidiosos do poder, educação e laços com um neoliberalismo selvagem que causa miséria, sofrimento e desigualdades maciças em riqueza, poder e renda. 0 trabalho de Freire não apenas oferece um desafio estimulante para as máquinas de desimaginação que produzem a cultura de morte e de miséria associada a tais regimes de direita, mas também torna a educação central para a política impregnada de possibilidades de luta coletiva e poderosas formas de resistência. A obra de Freire é perigosa, porque amplia e torna visiveis não apenas os parâmetros da opressão, especialmente sob o capitalismo neoliberal, mas também abrange a conexão entre fomentar a imaginação cívica e a coragem cívica, por um lado, e a luta pela resistência individual e coletiva pelo outro. A obra de Freire deixa claro que a crise da política é também a crise da educação e a crise de consciência. Além disso, a luta para mudar a consciência deve começar com o reconhecimento de que democracia e capitalismo não são a mesma coisa e que a luta pelo desenvolvimento de uma consciência anticapitalista é um ponto de partida para compreender e desafiar as culturas políticas que servem e reproduzem a forma atual de autoritarismo e da política fascista em ação no Brasil, Hungria, Turquia, Índia e, mais recentemente, na América de Donald Trump.

\section{Finalizando}

A pedagogia de Paulo Freire fornece base para um modo de vida no qual o conhecimento está ligado à compreensão da dor do outro, onde a ação está enraizada na necessidade de assumir riscos. 
A obra de Freire representa um território fronteiriço textual onde a poesia penetra na política e a solidariedade torna-se uma canção do presente iniciada no passado enquanto espera ser ouvida no futuro. (GIROUX, 1997b, p. 19).

0 tempo presente tem sido marcado por uma atmosfera social na qual confluem o negacionismo da ciência; a indiferença à dor de amigos e familiares de quase quinhentas ${ }^{5}$ mil vidas ceifadas pela Pandemia da COVID-19; privações de bens materiais e sociais de mais 14, 400 milhões de desempregados. Nessa conjuntura, ofensivas ultraconservadoras têm se revitalizado e, além da depreciação da educação pública e do pensamento crítico em geral, as teorias e princípios freireanos têm sido, de forma reiterada, desprezados, mediante gestos e narrativas que buscam desqualificar, mitigar ou interromper seu legado. No entanto, em sua coerência, entre o discurso e a prática, uma das lições mais belas que Paulo Freire nos ensinou diz respeito à esperança, substantivada na crença de que a realidade é dinâmica e de que homens e mulheres são seres inconclusos e, portanto, guardam consigo o germe da transformação de si e das suas realidades. Nesse contexto de distopias, dar visibilidade à práxis freireana é premente para contribuir com os processos de emancipação dos estratos empobrecidos e oprimidos mediante as incessantes lutas contra a opressão e dominação. Sob o prisma freireano, a luta é alimentada pela esperança, pois, em suas palavras:

Minha esperança é necessária, mas não é suficiente. Ela, só, não ganha a luta, mas sem ela a luta fraqueja e titubeia. Precisamos da esperança crítica, como o peixe precisa da água despoluída... Pensar que a esperança sozinha transforma o mundo e atuar movido por tal ingenuidade é um modo excelente de tombar na desesperança, no pessimismo, no fatalismo... É por isso que não há esperança na pura espera, nem tampouco se alcança o que se espera na espera pura, que vira, assim, espera vã. (FREIRE, 1992, p. 11).

Ao reconhecer a importância do legado das ideias de Paulo Freire, Giroux afirma que em um momento em que a memória está sendo apagada e a relevância política da educação é afastada pela medição e pela quantificação, seu exemplo é mais importante agora do que nunca:

[...] com as instituições públicas de educação básica e superior, cada vez mais, sob o cerco de uma série de forças neoliberais e conservadoras, é imperativo que os educadores se apropriem do entendimento de Freire sobre empoderamento e o potencial democrático da educação. (GIROUX, 2016, p. 297).

Assim, a esperança se faz verbo e se alia com o pensar crítico, com a luta, com as insubordinações e com a resistência, cujos movimentos são transversalizados pelo desejo da construção de um mundo com justiça social e dignidade humana. Qual sombra iremos escolher?

5- De acordo com a Agência Brasil, em 29 de maio de 2021, o Brasil contabiliza 461.931 mortes em decorrência da pandemia de covid-19. Disponível em: https://agenciabrasil.ebc.com.br/saude/noticia/2021-05/covid-19-brasil-registra-874-mortes-e-453-mil-casos-nas-ultimas-24h. Acesso em: 31 maio de 2021. 
Escolhi a sombra desta árvore para ${ }^{6 . .}$

Escolhi a sombra desta árvore para repousar do muito que farei, enquanto esperarei por ti. Quem espera na pura espera vive um tempo de espera vã. Por isto, enquanto te espero trabalharei os campos e

conversarei com os homens

Suarei meu corpo, que o sol queimará; minhas mãos ficarão calejadas; meus pés aprenderão o mistério dos caminhos; meus ouvidos ouvirão mais, meus olhos verão o que antes não viam, enquanto esperarei por ti. Não te esperarei na pura espera porque o meu tempo de espera é um tempo de que fazer. Desconfiarei daqueles que virão dizer-me, em voz baixa e precavidos:

É perigoso agir É perigoso falar É perigoso andar

É perigoso, esperar, na forma em que esperas, porquê êsses recusam a alegria de tua chegada. Desconfiarei também daqueles que virão dizer-me, com palavras fáceis, que já chegaste, porque êsses, ao anunciar-te ingênuamente , antes te denunciam.

Estarei preparando a tua chegada como o jardineiro prepara o jardim para a rosa que se abrirá na primavera.

Paulo Freire

\section{Referências}

BRASIL. Lei $n^{0}$ 12.612, de 13 de abril de 2012. Declara 0 educador Paulo Freire Patrono da Educação Brasileira. Brasília, DF: Presidência da República, 2012. Disponível em: http://www.planalto.gov.br/ ccivil_03/_ato2011-2014/2012/lei/12612.htm. Acesso em: 10 out. 2021.

CHAUÍ, M. Convite à filosofia. 13 ed. São Paulo: Ática. 2005.

FREI BETO. Paulo Freire: a leitura do mundo. In: FREIRE, Ana Maria Araújo. Paulo Freire: uma história de vida. Indaiatuba: Villa das Letras, 2006.

FREIRE, Paulo. Apresentação. In: GIROUX, Henry. Cruzando as fronteiras do discurso educacional: novas políticas em educação. Trad. Magda França Lopes. Porto Alegre: Artes Médicas Sul, 1999.

6- Paulo Freire, Genéve, março, 1971. Do acervo de Ana Maria Araújo Freire. Publicado em Pedagogia da indignação. São Paulo: Unesp, 2000. 
FREIRE, Paulo. Pedagogia da autonomia: saberes necessários à prática educativa. Rio de Janeiro; São Paulo: Paz e Terra, 2017.

FREIRE, Paulo. Pedagogia da esperança: um reencontro com a pedagogia do oprimido. Rio de Janeiro: Paz e Terra, 1992. https://doi.org/10.22294/eduper/ppge/ufv.v9i3.1108

FREIRE, Paulo. Prefácio. In: GIROUX, Henry. Teoria crítica e resistência em educação: para além das teorias de reprodução. Trad. Ângela Maria B. Biaggio. Petrópolis: Vozes, 1986.

GIROUX, Henry. Cruzando as fronteiras do discurso educacional: novas políticas em educação. Trad. Magda França Lopes. Porto Alegre: Artes Médicas Sul, 1999.

GIROUX, Henry. Os professores como intelectuais: rumo a uma pedagogia crítica da aprendizagem. Trad. Daniel Bueno. Porto Alegre: Artes Médicas Sul, 1997a.

GIROUX, Henry. Paulo Freire e a política do pós-colonialismo. Pátio, Porto Alegre, v. 1, n. 2, p. 15-19, ago./ out. 1997b.

GIROUX, Henry. Pedagogia crítica, Paulo Freire, e a coragem para ser político. Revista E-Curriculum, São Paulo, v. 14, n. 01, p. 296- 306 jan./mar. 2016. Disponível em: https://revistas.pucsp.br/index.php/ curriculum/article/view/27356. Acesso em: 13 maio 2021.

GIROUX, Henry. Teoria crítica e resistência em educação: para além das teorias de reprodução. Trad. Ângela Maria B. Biaggio. Petrópolis: Vozes, 1986.

LE GOFF, Jacques. História e memória. 5. ed. São Paulo: Copyright, 2003.

SANTIAGO, Eliete. Biografia. Recife: UFPE, [s. d]. Disponível em: http://www.catedrapaulofreireufpe.org/ memoria-paulo-freire/biografia. Acesso em: 11 maio 2021.

\section{Bibliografia em português do entrevistado}

GIROUX, Henry. Atos impuros: a prática política dos estudos culturais. Porto Alegre: Artmed, 2003.

GIROUX, Henry. Os professores como intelectuais: rumo a uma pedagogia crítica da aprendizagem. Trad. Daniel Bueno. Porto Alegre: Artes Médicas Sul, 1997.

GIROUX, Henry. Cruzando as fronteiras do discurso educacional: novas políticas em educação. Trad. Magda França Lopes. Porto Alegre: Artes Médicas Sul, 1999.

GIROUX, Henry. Escola crítica e política cultural. São Paulo: Cortez, 1987.

GIROUX, Henry. Teoria crítica e resistência em educação: para além das teorias de reprodução. Trad. Ângela Maria B. Biaggio. Petrópolis: Vozes, 1986. 
Maria Vieira Silva é doutora em educação pela Universidade Estadual de Campinas UNICAMP, com estágio pós-doutoral pelo Centre de Recherches Sociologiques et Politiques de Paris - Franca. É professora da Faculdade de Educação da Universidade Federal de Uberlândia com atuacão no Curso de Pedagogia e no Programa de Pỏs-graduação em Educação (Mestrado e Doutorado) desta mesma instituiçã̉o.

Maria Veranilda Mota Campos é doutora em educação pela Universidade Metodista de Piracicaba, com pós-doutoramento pela Universidade Federal de Minas Gerais. E professora do Departamento de Educação da Universidade Federal de Viçosa. 